\title{
The formation of doctoral schools in Europe in the condition of cross-border education
}

\author{
Mariya Skorobogatova ${ }^{1 *}$, Larisa Yagenich ${ }^{2}$, Yekaterina Siritsa $^{2}$, and Irina Kirillova ${ }^{2}$ \\ ${ }^{1}$ Vernadsky Crimean Federal University, department of social psychology, 295007 \\ Simferopol, Russia \\ ${ }^{2}$ Vernadsky Crimean Federal University, Institute of foreign philology, department of \\ foreign languages № 4, 295007 Simferopol, Russia
}

\begin{abstract}
Training of doctoral students is of special attention in the modern integration conditions of the higher education development. Trends of study of the doctoral schools development are necessary and practically in demand; absence of such investigations makes forecasting of the higher education in Russia difficult. Main tendencies of the doctoral schools formation and development were identified in this article: focus shifting of the questions solving from the national into the European level; applying of the modern methodological approaches system (studentcentered, interdisciplinary and competency based ones); responsibility increasing of the academic community for the doctoral students' training quality; implementation of thematic principles; interdisciplinary; interuniversity and international integration.
\end{abstract}

Top target of the higher education in Russia is modernization of the scientific staff training system in the conditions of the European and international integration. In order to achieve this aim Russian Federation joined Bologna Follow-up in 2003 that offered convergence and harmonization mechanisms of the European systems of higher education, regional and cross-border cooperation. That's why to study development trends of the scientific staff training system among the countries participating in the Bologna process is necessary and practically in demand. Absence of such kinds of investigations makes forecasting of the development of the Russian system of scientific staff training difficult in a large extent from successfully functioning of which Russia leading positions in world science and economics depend greatly.

Based on this the article aim is identification and analysis of features and main trends in the doctoral schools formation in the European countries under the conditions of the Bologna Follow-up.

Present-day trends in the formation and development of the doctoral schools in Europe are practically identical what is due to the processes of the European and international integration and standardization in the higher education.

\footnotetext{
${ }^{*}$ Corresponding author: maricrimea@gmail.com
} 
Higher education system analysis of the European countries offers to separate 3 main control models of the doctoral schools: centralized one (Italy), partially-centralized one (France) and decentralized one (Great Britain; Germany).

In Italy Ministry of education, universities and scientific investigations deals with the development strategy of the doctoral schools, supporting their interaction with foreign universities. Opening and functioning of the doctoral schools is possible only after getting academic accreditation validity period of which is fixed individually for every university (up to 5 years). Doctoral school should fulfill the qualifications of practicability determination of its opening, namely: to have necessary academic staff; research and production equipment; available scholarships; adequate and sustainable financing; possibility to provide interdisciplinary education. After having received this accreditation, education content is checked periodically for compliance with the academic standards.

Maintaining certain autonomy, Universities in France pass this verification procedure of doctoral schools once every 4 years which is done by the Ministry of higher education and scientific studies. In case of successful one they receive financing from the state budget, right for doctoral programs realization and awarding of doctoral degrees of state standard. Main criteria for the contract conclusion (prolongation) are the connection of the scientific project of the doctoral school with the university long-term strategic plans, its scientific investigation quality and graduates employment.

Doctoral schools of Germany and Great Britain have decentralized management system. Demands for the doctoral students' training may be vary both in every university and faculty. As a result of different-sided autonomy, the universities are in intense rivalry for the doctoral school quality and an amount of its doctoral students, so they are themselves interested in upgrading of their standards. Scientific degree status and value is determined by the university authority which awards it.

In Germany the universities have different sided autonomy in the points of doctoral students' training and awarding them a degree based on laws on higher education adopted by the territories. "Basic law" which is the legislative basis of the German higher education system, has the following notions: "Art and science, investigation and teaching are free" [1, p. 215-237].

In Great Britain both the university and every faculty are entitled to work out their main criteria and demands for the doctoral students' training system. However, according to Quality Assurance Agency for higher Education concepts "doctoral school is first of all an environment that provides support for doctoral students' studies and where highly quality investigations are carried out". They reflect typical factors that determine it:

- obvious scientific achievements;

- sufficient number of researchers and doctoral students;

- free access for consultations with senior colleagues - professors;

- an availability of the necessary material and technical base;

- having possibility to discuss the questions and problems informally (with professors who aren't their official scientific supervisor and with other doctoral students);

- controlling of the ethical problems, emphasizing the scientific- investigative skills development and those qualities which can be helpful during an employment [2, p. 215259].

Due to historically formed traditions, in all European countries the university has an exclusivity right to train doctoral students and to award them degrees. Under conditions of sciences integration, internationalization of academic programs the trend of diversification of doctoral education on a structurally substantive level is observed in the universities of Europe. So that nowadays there are 3 main forms of post-doctoral organization in examining countries: individual education, doctoral studies and doctoral school. Every university can have both one and all three forms. 
Individual education means absence of an educational component, but does not exclude it.

Doctoral studies include doctoral students and often masters. Its aim is to provide an administrative support for the students, to organize their understanding of universal competencies, to enroll the students (doctoral ones), to provide them with classes, and also to be fully responsible for quality of their education.

Doctoral school is an organized structure working only for doctoral students which is centered on concrete subject (research field) or investigation topic, or interdisciplinary point. It is project-oriented and can provide the establishment of research groups / networks; they can have several universities in them.

Doctoral schools predominate in France and Great Britain, there is about equal number of them and doctoral studies in Italy but in Germany individual form of doctoral students' education prevails over [3, p. 149-157].

Doctoral schools development is carried out in cooperation with the research organizations, business-structures, with other universities, including foreign ones.

Advantages for the collaboration between the doctoral schools and scientific- research organizations are:

- possibility to carry out their research at the conditions of more developed infrastructure;

- increased financing;

- obtaining of practical experience, professional meetings that can reflect in the job prospects.

Doctoral schools collaboration with business structures is firstly connected with the private companies interest in perspectives to obtain new ideas, innovative developments. Cooperating with the universities, business structures are the customers for not only scientific research but also for those competences which, to their mind, future highlyqualified specialists should have. Such kind of collaboration expands perspectives for the doctoral students in further employment and financing of their scientific work. Partnership issues in the doctoral students' training system between universities and business structures were widely considered by European university association in the «DOC-CAREERS Project» [4, p.57-63]. Government of these countries is highly interested in cooperation of the doctoral schools with business structures. Its assistance is stated in tax, credit and other finance terms, pump priming for the manufactured products, credit activities, loan insurance system. In France National agency for working of inventions offsets all costs for incorporating new techniques within $25-30 \%$ of money amount spent on it for the small and medium-sized enterprises and it also settles up to $50 \%$ of their expenses spent for scientific research connected with new products and technologies development.

Vivid example of contract formation between doctoral student and business is France experience where agreement project between Ministry of education and private companies was worked out on the governmental level, aiming to prepare scientific researches which was named "Cifre". From one hand, this program "Cifre" provides large companies with an access to the advanced investigations; from the other hand, it helps doctoral students to gain work experience from the point of view of their future employment. Such contracts for education in the field of investigation study are directed for the state private partnership development which is based on conducting a research project. Every year an amount of doctoral students, signed "Cifre", increases because they receive high salary, research expertise, specialized laboratories, guaranteed employment, but a company, in its turn, gets annual fixed grant from the government. When signing up this contract, an important advantage for the doctoral student is a high percentage of thesis defending on time and quick employment. The most popular scientific fields in cooperation lines with "Cifre" are IT-technologies, engineering sciences, human sciences, chemistry and social ones [2, $\mathrm{p}$. 245-260]. 
Bright illustration of the cooperation between doctoral schools and business-structures in Germany is formation of the research group between the largest automobile concern in terms of turnover «Daimler AG» and Technological institution Karlsruhe in BadenWürttemberg. «Daimler» chooses and finances 9 doctoral students with total amount of money of 1,75 million euros during 4 years. Joint program is directed on the development of the electromotive cars and technologies of future. It regularly employs doctorants who are the best in the field of their subjects. Doctoral students carry out research work in the university with professors and they participate in the investigative and developmentreconstructive works parallel with company representatives. They are controlled by the university with «Daimler» ones. The main part of this academic program is the point that a doctoral student must spend 3 months abroad in the foreign companies and scientific institutions which deal with the electromotive car.

In Italy Government carries out a policy of economic benefits for the private companies which take part in the doctoral students' training. In particular, they canceled estate duty, income tax; they also increased income limits, partial tax free. However, as Italy is one of the few developed countries where persons with a degree have very few places to work at, it hasn't already have a positive effect.

In the European countries one can observe the networking trend between the doctoral schools both inside the country and outside of it. This is due to the development of doctoral student mobility, interdisciplinarity of academic programs, similar problems in the fundamental research fields. The status and prestige of a European university is determined by the number of partner universities.

Admission requirements to the doctoral school are practically identical in all European countries. The main point is a master's degree. But there are some cases when you can enter the third level of higher education without master's degree diploma. This is especially common for UK and Germany. Besides it's necessary to provide a standard for all countries a package of documents which includes $\mathrm{CV}$; research project with a review of a potential supervisor; an approval of the dissertation project at least by 2 reviewers; the list of articles (if there are any); recommendation letters; in some areas of science, such as medicine, dentistry or some pedagogical ones, a state exam is taken [2, p. 149-151].

In European countries there are some features for choice and cooperation with the supervisor. In France, a supervisor is appointed to a doctoral student by the academic council or administration of a doctoral school. The same is in Italy also but only after the probation term. In Great Britain an Advisor is appointed to the doctoral student parallel with the Supervisor. The choice of advisor greatly depends on the doctoral student himself.

Besides there are frequent cases when 2 supervisors are appointed to the doctoral student: one helps and controls only educating process; another one controls doctoral thesis writing. In Germany due to continuing individual model of training scientific staff, supervisor choosing is done by the doctoral student independently.

Development trend of the institute of co-management of scientific research is observed in all examining countries. It's of current interest in the conditions of doctoral schools collaboration with other universities, research organizations and business structures.

Requirements for the first (main) supervisor are the strictest ones as he the most important one in the scientific staff training, but style of scientific cooperation, an amount of consultations greatly determines the result of the doctoral thesis completion. Cosupervisor can be a representative from other, including foreign university or the one from non-academic field of work.

The principals of the scientific supervising are free help, cooperation with other researchers, consultation with independent investigators both internal and external one, mechanisms which can protect a doctoral student if he loses his supervisor. 
Tendency of the requirements increasing for the level of the scientific supervisors' professional competence are observed in European countries, mainly: additional degree (a diploma of the "habilitation doctor" (Germany, France)), scientific leadership experience as co-supervisor and significant scientific achievements: conference participation, availability of monographs, articles in the scientific magazines, teaching experience.

The main UK feature is an academic program for the starting supervisors. They are directed for achieving professional and personal competencies allowing you to manage doctoral students affectively. For this purpose, the universities conduct seminars and trainings, publish methodological guidelines where all supervisors' all of the rights and obligations, possible pedagogical situations are described in details [5, p. 317-329].

The number of doctoral students per supervisor is not strictly regulated, but on average it is from 3 to 6 people. It depends on science area, professional and personal supervisor's qualities. Successful supervising, namely doctoral thesis defense in time, is one of the indicators for job promotions of university research staff.

Academic programs in the doctoral schools are the main differentia comparing to all previous university history. Educating program as a compulsory element of the doctoral school started from 2003.

According to the principals of the doctoral school's development established within the Bologna process ("Salzburg Principles") academic programs should include:

- competency-based and student-centered approaches;

- focusing on getting additional competencies meeting the scientific demands and employment market;

- a variety of educational programs, their interdisciplinary type; time regulation $[5, \mathrm{p}$. 219-305].

There is no unified educational model for the scientific staff training in the European countries but there is a number of identical trends. Academic programs include an advanced disciplinary and interdisciplinary training in the form of the special courses and seminars, elective and basic disciplines aimed on the formation of the scientific, professional and personal competencies that are necessary for the successful doctoral thesis completing and subsequent professional career. Combination of the educating component and doctoral thesis work can be combined in different ways. In the first case both stages are carried out in parallel. In the second one the work over the doctoral thesis may be started only after successful completion of the educating component what is proved by passing of the appropriate examinations. In any of mentioned above variants a doctoral student study all academic programs during the 1-st or often on the 1-2 years of study. The 3-rd year is dedicated for the work on the doctoral thesis.

As a rule, academic programs consist of 3 sets:

- educative-research unit which is directed for acquiring the advanced academic and investigating competencies which are necessary for the scientific work;

- professional one which is oriented on the competencies establishing which are necessary for future employment;

- unit of the personal competencies which is necessary for the individual development of the doctoral student.

The 1-st and 2-nd units are marked in the academic program and have time limit; the 3rd one is usually of the elective type but it's of great interest among both the doctoral students and university teaching staff.

According to European Credit Transfer System all subjects have their own "value". Every doctoral school determines the total number of the credits necessary for the successful completing of the academic program. Disciplines choosing in every unit depends on the thematic scope of every doctoral school, research topic, having a scientific experiment, 
supervisor's recommendations, future employment, individual possibilities and interests, and so on.

Personal development unit can be held both in a team of researchers and individually with a professor (trainer). Course duration is different: from 1 hour up till several months.

Therefore, analysis of the doctoral schools formation in Europe in the context of crossborder education made it possible to identify and to go into the question in large the following trends:

- shift in emphasis of quality points for the doctoral students' training from the national on the European-wide level;

- university responsibility increasing for quality of doctoral candidates' training, timeliness for thesis defense, employment of the doctoral school graduates;

- principals implementation of thematic focus, interdisciplinarity and inter-university and international integration in the formation of doctoral schools;

- improving of the partnership institution of the doctoral students' training by strengthening of the internal and international integration in the university community, attracting the research organizations, business structures, professional practitioners and representatives of the non-educational professions;

- requirement increasing for the supervisors, development and optimization of the institute of the co-management with the scientific research.

\section{References}

1. Education at a Glance. OECD indicators (OECD Publishing, Paris, 2018)

2. Research and Innovation performance in the EU. Innovation Union progress at country level (European Commission, Brussels, 2014)

3. U. Schreiterer, Higher Education in Europe. Comparing Doctoral Training in Europe and North America. XXXIII, 149-157 (2008)

4. L. Borrell-Damian, R. Morais, J. H. Smith, Collaborative Doctoral education in Europe: research partnerships and employability for researchers. Report on DOCCAREERS II Project. European University Association (European University Association, Brussels, 2015)

5. The European Higher Education Area in 2018: Bologna Process Implementation Report (Publications Office of the European Union, Luxembourg, 2018) 